\title{
Cardiac arrest in COVID-19 myocarditis: a case report
}

\section{Mia Dubravčić*, - Kristina Gašparović, (1)Tihana Balaško Josipović, (C) Mia Rora, -Rajka Gabelica, CMaja Hrabak Paar, -Daniel Lovrić}

University of Zagreb School of Medicine, University Hospital Centre Zagreb, Zagreb, Croatia

\begin{abstract}
KEYWORDS: COVID-19, myocarditis, out-of-hospital cardiac arrest. CITATION: Cardiol Croat. 2021;16(5-6):177. | https://doi.org/10.15836/ccar2021.177

*ADDRESS FOR CORRESPONDENCE: Mia Dubravčić, Klinički bolnički centar Zagreb, Kišpatićeva 12, HR-10000 Zagreb, Croatia. / Phone: +385-98-9549-898 / E-mail: dubravcic.mia@gmail.hr

ORCID: Mia Dubravčić, https://orcid.org/0000-0003-0441-4772 • Kristina Gašparović, https://orcid.org/0000-0002-1191-4831 Tihana Balaško Josipović, https://orcid.org/0000-0002-0251-9960 • Mia Rora, https://orcid.org/0000-0001-7624-1554 Rajka Gabelica, https://orcid.org/0000-0003-2170-419X • Maja Hrabak Paar, https://orcid.org/0000-0002-0390-8466 Daniel Lovrić, https://orcid.org/0000-0002-5052-6559
\end{abstract}

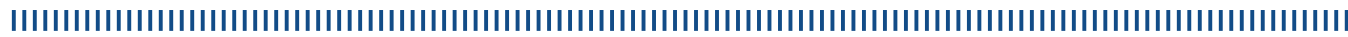

Introduction: Coronavirus disease 2019 (COVID-19) was first described in China, in patients with flu-like symptoms in December $2019^{1}$. This family of viruses is known for its cardiotropism² ${ }^{2}$ Arrhythmia is possible clinical manifestation in COVID-19 patients and several cases of COVID-19 myocarditis have been reported, some as a cause of death ${ }^{3}$.

Case report: We present a case of a 37-years old, previously healthy, female patient who was admitted to COVID-19 Intensive care unit (ICU) at University Hospital Centre Zagreb after out of hospital cardiac arrest and successful resuscitation. She manifested episodes of chest pain and palpitations during two months prior to cardiac arrest. Initial laboratory findings showed elevated levels of high-sensitive troponin I and NT-proBNP, significant hypokalemia and normal values of C-reactive protein. Additional urgent work-up (pulmonary CT angiography and brain CT scan) showed no significant pathology and Sars-Cov-2 PCR RNA test came positive, without respiratory involvement. Due to ECG changes and ultrasound finding of reduced left ventricular ejection fraction (LVEF 25-30\%) with anteroseptal and apical akinesia and inferior hypokinesia, urgent coronary angiography was performed, there were no signs of coronary artery disease, and the suspected diagnosis was Takotsubo cardiomyopathy or myocarditis. Soon after admission heart failure therapy was introduced, and follow-up echocardiography showed improvement in LVEF (40-45\%). Patient was given no specific antiviral treatment nor corticosteroid therapy. Additional work-up regarding serology for cardiotropic viruses came negative, and IgG antibodies for Covid-19 showed borderline result. Cardiac magnetic resonance imaging (MRI) performed 18 days after initial event described recovered left ventricular ejection fraction (LVEF 53\%), with mild hypokinesia, oedema and mid-wall late gadolinium enhancement in apical 2/3 of anterior, anteroseptal and anterolateral wall, with pattern characteristic for myocarditis (Figure $\mathbf{1})^{4}$. At follow-up, one month after discharge, patient is completely recovered, without signs of heart failure or arrhythmias, with preserved LVEF and normal NTproNBP levels.
RECEIVED:

March 28, 2021

ACCEPTED:

April 2, 2021

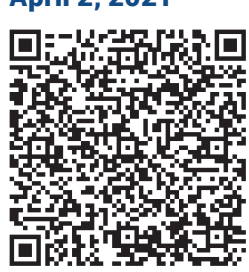

Conclusion: This case once again highlights cardiac complications of SARS-CoV-2 infection, without respiratory involvement. Also, it shows good prognosis without specific antiviral treatment, emphasizing importance of early introduction of heart failure therapy.

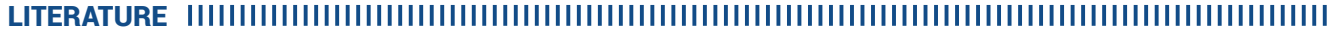

1. Zhu N, Zhang D, Wang W, Li X, Yang B, Song J, et al; China Novel Coronavirus Investigating and Research Team. A Novel Coronavirus from Patients with Pneumonia in China, 2019. N Engl J Med. 2020 Feb 20;382(8):727-733. https://doi.org/10.1056/NEJMoa2001017

2. Agrawal AS, Garron T, Tao X, Peng BH, Wakamiya M, Chan TS, et al. Generation of a transgenic mouse model of Middle East respiratory syndrome coronavirus infection and disease. J Virol. 2015 Apr;89(7):3659-70. https://doi.org/10.1128/JVI.03427-14

3. Ruan Q, Yang K, Wang W, Jiang L, Song J. Clinical predictors of mortality due to COVID-19 based on an analysis of data of 150 patients from Wuhan, China. Intensive Care Med. 2020 May:46(5):846-848. https://doi.org/10.1007/s00134-020-05991-x

4. Puntmann V0, Carerj ML, Wieters I, Fahim M, Arendt C, Hoffmann J, et al. Outcomes of Cardiovascular Magnetic Resonance Imaging in Patients Recently Recovered From Coronavirus Disease 2019 (COVID-19). JAMA Cardiol. 2020 Nov 1;5(11):1265-1273. https://doi.org/10.1001/jamacardio.2020.3557 